\title{
KAJIAN KEBUTUHAN AIR BERSIH DAN \\ PERENCANAAN KAPASITAS RESERVOIR PADA WILAYAH KEPULAUAN (Studi Kasus: Pulau Mandangin Madura)
}

\author{
Nurul Jannah Asid ${ }^{1)}$ \\ 1) Prodi Teknik Sipil, Universitas Dr. Soetomo,nuruljannahasid@gmail.com
}

\begin{abstract}
Mandangin Island is one of the islands in Sampang District, Sampang Regency. In Mandangin Island, there is no water distribution to fulfill clean water for the Resident. So that many resident make use of rainwater that is accommodated for domestic water need and consumption.In 2014, the Ministry of Public Works developed a sea water distillation systemusing a membrane technology called SWRO, however only fullfill drinking water for resident.

There need analysis to find out the Resident's clean water needs as one of the studies in planning a Clean Water Distribution System. In this study, the first is analysis of the existing population, from the available data, a statistical method that is suitable for the prediction of the population is the Geometric Method.The results of the study in 2023 The population is 20694 and $100 \%$ of the population served by clean water.In the same year, domestic clean water needs were $1779.6 \mathrm{~m} 3 / \mathrm{s}$, serviced by house connection pipe was $1655.5 \mathrm{~m} 3 / \mathrm{s}$, while with public hydrants $124.16 \mathrm{~m} 3 / \mathrm{s}$, non-domestic water needs $355.93 \mathrm{~m} 3 / \mathrm{s}$. The average water demand per day after calculated with water loss is $2562.7 \mathrm{~m} 3 / \mathrm{s}$. From the evaluation of debit loading, the current debit must be increased, from the original $5 \mathrm{l} / \mathrm{s}$ to $30 \mathrm{l} / \mathrm{s}$. Based on data analysis, the reservoir capacity for water needs is $200 \mathrm{~m} 3$
\end{abstract}

Keyword: Water demand, Reservoir, Mandangin island.

\begin{abstract}
ABSTRAK
Pulau Mandangin merupakan salah satu kepulauan yang berada di Kecamatan Sampang Kabupaten Sampang. Saat ini, di Pulau Mandangin belum terdapat jaringan air bersih untuk memenuhi air bersih bagi penduduk pulau. Sehingga banyak penduduk pulau memanfaatkan air hujan yang ditampung untuk mandi, mencuci dan konsumsi. Pada Tahun 2014, Kementrian PU membangun sistem penyulingan air laut mengggunakan teknologi membran yang disebut SWRO, Namun SWRO hanya menjamin kebutuhan air minum. Perlu adanya analisis untuk mengetahui kebutuhan air bersih penduduk sebagai salahsatu studi dalam merencanakan Sistem Distribusi Air Bersih.Pada penelitian ini dilakukan analisis data jumlah penduduk yang ada, dari data yang ada dapat diketahui metode statistik yang sesuai untuk prediksi jumlah penduduk tahun yang akan datang adalah Metode Geometrik. Hasil dari penelitian pada tahun 2023 Jumlah penduduk 20694 Jiwa dengan jumlah penduduk yang terlayani air bersih adalah 100\%. Pada Tahun yang sama kebutuhan air bersih domestik $1779.6 \mathrm{~m} 3 / \mathrm{dtk}$, dilayani dengan sambungan rumah adalah $1655.5 \mathrm{~m} 3 /$ dtk sedangkan dengan hidran umum $124.16 \mathrm{~m} 3 /$ dtk dan kebutuhan air non domestik $355.93 \mathrm{~m} 3 / \mathrm{dtk}$. Kebutuhan air rata-rataperhari setelah di hitung dengan kehilangan air adalah 2562.7 m3/dtk. Dari evaluasi pembebanan debit, maka debit yang ada saat ini harus ditingkatkan, dari yang semula 5 l/dtk menjadi $30 \mathrm{l} / \mathrm{dtk}$. Berdasarkan analisis data didapatkan kapasitas reservoir yang sesuai untuk kebutuhan air adalah $200 \mathrm{~m} 3$
\end{abstract}

Kata Kunci: Kebutuhan air, Reservoir, Pulau Mandangin. 


\section{NAROTAMA JURNAL TEKNIK SIPIL \\ e-ISSN: $2460-3430$ \\ VOLUME 3 NOMOR 2 NOVEMBER 2019}

\section{PENDAHULUAN}

Air bersih merupakan kebutuhan pokok bagi manusia. Hampir seluruh aktivitas manusia membutuhkan air bersih. Kebutuhan air akan meningkat seiring pertumbuhan penduduk. Sarana penyediaan air bersih harusnya melayani kebutuhan pada daerah desa maupun daerah kota. Air Bersih adalah air yang bermutu baik sesuai dengan syarat untuk memenuhi kebutuhan manusia termasuk untuk konsumsi dan untuk sanitasi.

Pulau Mandangin merupakan salah satu Kepulauan setingkat Desa yang ada di Kecamatan Sampang Kabupaten Sampang Madura. Kebutuhan air bersih disana dipenuhi dengan air hujan yang ditampung ketika musim hujan termasuk air untuk minum. Jika kemarau panjang melanda masyarakat membeli air dari luar pulau dengan harga tinggi atau memanfaatkan air laut tanpa proses pengolahan. Semenjak tahun 2014 Pihak PU Cipta Karya pusat telah membangun Unit pengolahan air laut untuk kebutuhan air minum warga yang disebut SWRO (Sea Water Reserve Osmosis). Namun, SWRO hanya mampu untuk memenuhi kebutuhan air minum yang dialirkan pada tiap depo air minum. Sehingga warga masih harus berpikir untuk memenuhi kebutuhan air bersih.

Untuk memenuhi kebutuhan air bersih di Pulau Mandangin, maka perlu dilakukan analis kebutuhan air sebagai studi awal. Pada penelitian ini juga akan dilakukan perencanaan kapasitas reservoir untuk memenuhi kebutuhan air bersih. diharapkan penelitian ini bisa dijadikan salah satu acuan dalam perencanaan jaringan air bersih di Pulau Mandangin untuk memenuhi kebutuhan air Bersih bagi masyarakat Pulau Mandangin.

\section{METODE PENELITIAN}

\section{DIAGRAM ALIR}

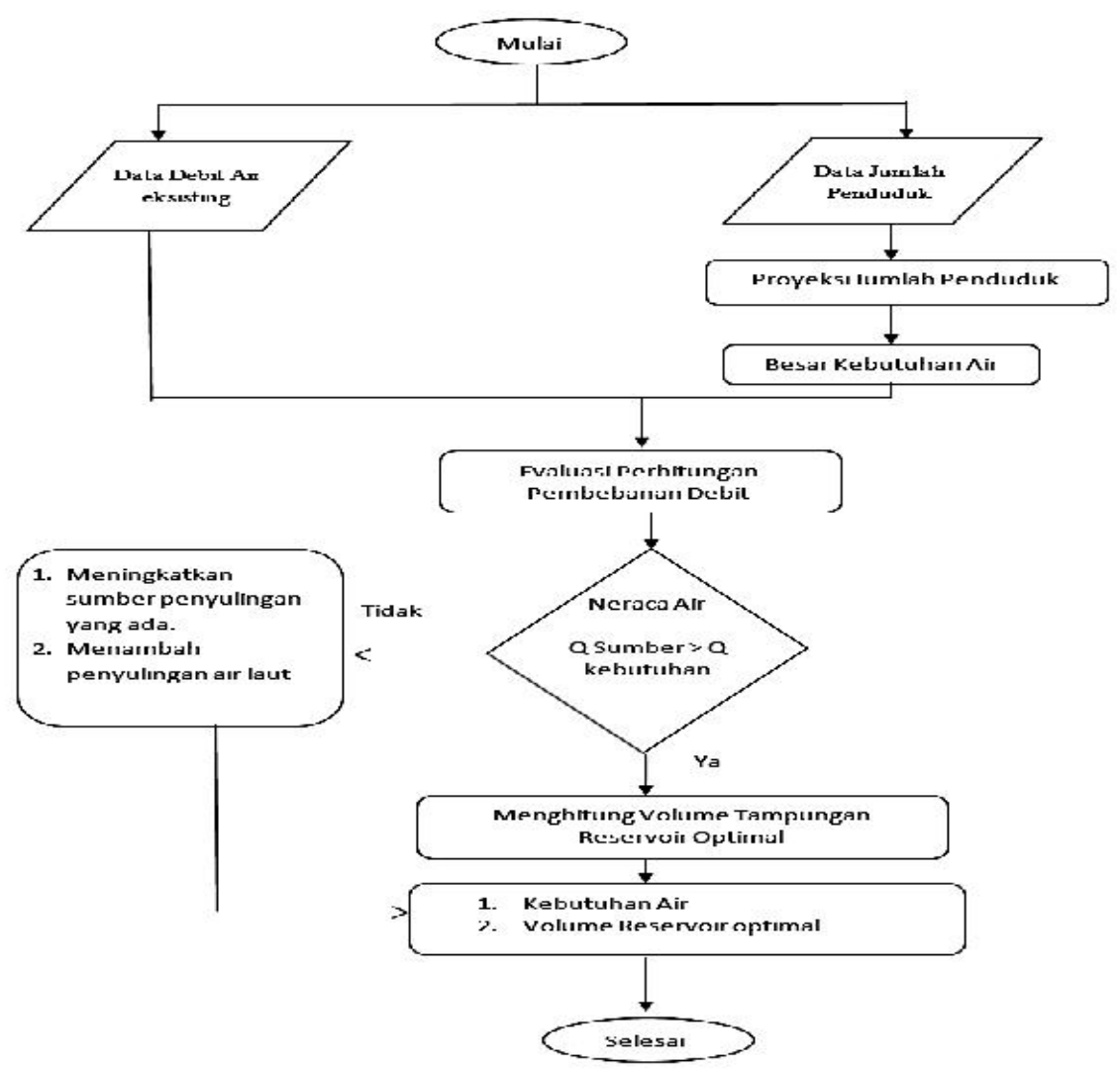

Gambar 1. Diagram AlirPenelitian 


\section{PENGUMPULAN DATA}

Data Primer

a. Survei Jaringan Air minum

Data Sekunder

a. Data Debit Air Eksisting dari SWRO

b. Data Jumlah Penduduk

c. Data kebutuhan air

\section{HASIL PENELITIAN DAN PEMBAHASAN}

\section{- Jumlah Penduduk}

Jumlah penduduk didapat dari data BPS kemudian dilihat dari tren statistik maka ditetentukan metode apa yang paling cocok untuk menghitung proyeksi jumlah penduduk. Berdasarkan data jumlah penduduk Pulau Mandangin dari tahun 2010-2018, didapatkan Metode yang paling sesuai adalah Metode Geometrik, sehingga dilakukan perhitungan proyeksi jumlah penduduk Pulau Mandangin untuk tahun 2019-2023 dengan Metode Geometrik.

Tabel 1. Proyeksi Jumlah Penduduk Pulau Mandangin

\begin{tabular}{|c|l|c|c|c|c|c|}
\hline \multirow{2}{*}{ No. } & \multirow{2}{*}{ Kelurahan } & \multicolumn{5}{|c|}{ Jumlah Penduduk (Jiwa ) } \\
\cline { 3 - 7 } & & $\mathbf{5 0 1 9}$ & $\mathbf{2 0 2 0}$ & $\mathbf{2 0 2 1}$ & $\mathbf{2 0 2 2}$ & $\mathbf{2 0 2 3}$ \\
\cline { 3 - 7 } & & 20383 & 20460 & 20538 & 20616 & 20694 \\
\hline 1 & Pulau Mandangin & 2038 &
\end{tabular}

Sumber: Hasil Perhitungan, 2019

- Jumlah Penduduk Terlayani

Jumlah penduduk terlayani didapatkan dari presentase target penduduk yang ingin dilayani dikalikan dengan jumlah total penduduk.

Tabel 2. Jumlah Penduduk Terlayani

\begin{tabular}{|c|l|c|c|c|c|c|c|}
\hline No & Uraian & Satuan & $\mathbf{2 0 1 9}$ & $\mathbf{2 0 2 0}$ & $\mathbf{2 0 2 1}$ & $\mathbf{2 0 2 2}$ & $\mathbf{2 0 2 3}$ \\
\hline 1 & $\begin{array}{l}\text { Jumlah } \\
\text { Penduduk }\end{array}$ & Jiwa & 20383 & 20460 & 20538 & 20616 & 20694 \\
\hline 2 & $\begin{array}{l}\text { Presentase } \\
\text { Pelayanan }\end{array}$ & $\%$ & 100 & 100 & 100 & 100 & 100 \\
\hline 3 & $\begin{array}{l}\text { Jumlah } \\
\text { Penduduk } \\
\text { Terlayani }\end{array}$ & Jiwa & 20383 & 20460 & 20538 & 20616 & 20694 \\
\hline
\end{tabular}

Sumber: Hasil Perhitungan, 2019

- Kebutuhan Air Untuk Sambungan Rumah

Kebutuhan air untuk sambungan rumah adalah perhitungan kebutuhan air masyarakat yang bisa dilayani dengan sambungan rumah. 
Tabel 3. Kebutuhan Air Untuk Sambungan Rumah

\begin{tabular}{|c|l|c|c|c|c|c|c|}
\hline No & \multicolumn{1}{|c|}{ Uraian } & Satuan & 2019 & 2020 & 2021 & 2022 & 2023 \\
\hline 1 & $\begin{array}{l}\text { Presentase } \\
\text { Sambungan Rumah }\end{array}$ & $\%$ & 80 & 80 & 80 & 80 & 80 \\
\hline 2 & $\begin{array}{l}\text { Jumlah penduduk } \\
\text { terlayani dengan } \\
\text { SR }\end{array}$ & Jiwa & 16306 & 16368 & 16430 & 16493 & 16555 \\
\hline 3 & $\begin{array}{l}\text { Jumlah Sambungan } \\
\text { Rumah }\end{array}$ & Unit & 1631 & 1637 & 1643 & 1649 & 1656 \\
\hline 4 & $\begin{array}{l}\text { Standart Kebutuhan } \\
\text { Air Bersih Untuk SR }\end{array}$ & $\begin{array}{c}\text { Itorang/ } \\
\text { hari }\end{array}$ & 100 & 100 & 100 & 100 & 100 \\
\hline 5 & $\begin{array}{l}\text { Kebutuhan Air pada } \\
\text { SR }\end{array}$ & m3/har & 1630.6 & 1636.8 & 1643.0 & 1649.3 & 1655.5 \\
\hline
\end{tabular}

Sumber: Hasil Perhitungan, 2019

\section{- Kebutuhan Air Untuk Hidran Umum}

Kebutuhan air untuk hidran adalah perhitungan kebutuhan air masyarakat yang tidak bisa dilayani dengan sambungan rumah, maka dilayani dengan hidran umum.

Tabel 4. Kebutuhan Air Untuk Hidran Umum

\begin{tabular}{|c|l|c|c|c|c|c|c|}
\hline No & \multicolumn{1}{|c|}{ Uraian } & Satuan & $\mathbf{2 0 1 9}$ & $\mathbf{2 0 2 0}$ & $\mathbf{2 0 2 1}$ & $\mathbf{2 0 2 2}$ & $\mathbf{2 0 2 3}$ \\
\hline 1 & Presentase Hidran Umum & $\%$ & 20 & 20 & 20 & 20 & 20 \\
\hline 2 & Jumlah Penduduk terlayani dengan HU & Jiwa & 4076.6 & 4092 & 4107.6 & 4123.2 & 4138.8 \\
\hline 3 & Standart kebutuhan air untuk HU & $\begin{array}{c}\text { lt/orang/ } \\
\text { hari }\end{array}$ & 30 & 30 & 30 & 30 & 30 \\
\hline 4 & Jumlah Hidran Umum & Unit & 20.383 & 20.46 & 20.538 & 20.616 & 20.694 \\
\hline 5 & Kebutuhan air pada Hidran umum & m3/hari & 122.29 & 122.76 & 123.22 & 123.69 & 124.16 \\
\hline
\end{tabular}

Sumber:Hasil Perhitungan, 2019

\section{- Kebutuhan Air Perhari}

Kebutuhan air bersih perhari adalah kebutuhan air total antara kebutuhan air domestik dan non domestik. Kebutuhan air domestik adalah kebutuhan air untuk kegiatan domestik yang bisa dipenuhi dengan sambungan rumah dan hidran umum. Kebutuhan air non domestik adalah kebutuhan air untuk kegiatan air untuk sekolah atau sosial.

Tabel 5. Kebutuhan Air Perhari

\begin{tabular}{|c|c|c|c|c|c|c|c|}
\hline No & Uraian & Satuan & $\mathbf{2 0 1 9}$ & $\mathbf{2 0 2 0}$ & $\mathbf{2 0 2 1}$ & $\mathbf{2 0 2 2}$ & $\mathbf{2 0 2 3}$ \\
\hline 1 & $\begin{array}{c}\text { Kebutuhan air } \\
\text { Domestik }\end{array}$ & $\mathrm{m} 3 /$ hari & 1752.9 & 1759.5 & 1766.3 & 1772.9 & 1779.6 \\
\hline 2 & $\begin{array}{c}\text { Kebutuhan air } \\
\text { non domestik }\end{array}$ & $\mathrm{m} 3 /$ hari & 350.58 & 351.91 & 353.25 & 354.59 & 355.93 \\
\hline 3 & $\begin{array}{c}\text { Kebutuhan air } \\
\text { perhari }\end{array}$ & $\mathrm{m} 3 /$ hari & 2103.6 & 2111.5 & 2119.5 & 2127.6 & 2135.6 \\
\hline
\end{tabular}

Sumber:Hasil Perhitungan, 2019 


\section{- Kehilangan Air dan Fluktuasi Kebutuhan Air}

Kehilangan air adalah jumlah air yang hilang karena berbagai masalah misalnya kebocoran dan tidak sampai pada penduduk yang harus dilayani atau kesalahan pencatatan. Kebutuhan air rata-rata perhari adalah kebutuhan air rata-rata perorang selama 24 jam setelah ditambah dengan kehilangan air. Kebutuhan air maksimal adalah kebutuhan air total dikalikan dengan faktor pengali maksimal yaitu 1,1. Sedangkan kebutuhan air jam puncak adalah kebutuhan air total yang dikalikan dengan faktor pengali jam puncak yaitu 1,5 .

Tabel 6. Kehilangan Air dan Kebutuhan Air Rata-Rata, Maksimal dan Jam Puncak

\begin{tabular}{|l|l|c|c|c|c|c|c|}
\hline No & Uraian & Satuan & $\mathbf{2 0 1 9}$ & $\mathbf{2 0 2 0}$ & $\mathbf{2 0 2 1}$ & $\mathbf{2 0 2 2}$ & $\mathbf{2 0 2 3}$ \\
\hline 1 & $\begin{array}{l}\text { Presentase } \\
\text { kehilangan air }\end{array}$ & $\%$ & 20 & 20 & 20 & 20 & 20 \\
\hline 2 & $\begin{array}{l}\text { Kehilangan } \\
\text { Air }\end{array}$ & $\mathrm{m} 3 /$ hari & 420.71 & 422.29 & 423.90 & 425.51 & 427.12 \\
\hline 3 & $\begin{array}{l}\text { Kebutuhan Air } \\
\text { rata-rata } \\
\text { perhari }\end{array}$ & $\mathrm{m} 3 /$ hari & 2524.2 & 2533.7 & 2543.4 & 2553.1 & 2562.7 \\
\hline 5 & $\begin{array}{l}\text { Kebutuhan air } \\
\text { maksimal per } \\
\text { hari }\end{array}$ & $\mathrm{m} 3 /$ hari & 2776.6 & 2787.1 & 2797.7 & 2808.2 & 2819.1 \\
\hline 5 & $\begin{array}{l}\text { Kebutuhan air } \\
\text { pada jam } \\
\text { puncak }\end{array}$ & m3/hari & 3786.4 & 3800.6 & 3815.1 & 3829.6 & 3844.1 \\
\hline
\end{tabular}

Sumber:Hasil Perhitungan, 2019

\section{- Evaluasi Perhitungan Pembebanan Debit}

Evaluasi pembebanan debit adalah neraca air untuk membandingkan debit kebutuhan air dengan debit air disumber dalam hal ini air output dari SWRO. Berdasarkan data yang didapatkan dari jurnal yang dikeluarkan oleh PU Cipta Karya Pusat tahun 2014 disebutkan bahwa debit keluaran dari SWRO adalah 5 1/dtk. Kebutuhan air rata-rata adalah 29 1/dtk sehingga debit harus ditingkatkan menjadi 30 l/dtk.

\section{- Perhitungan Kapasitas Reservoir}

Perhitungan kapasitas Reservoir berdasarkan kebutuhan air total, kemudian dilakukan simulasi untuk merencanakan reservoir untuk memenuhi kebutuhan air sepanjang hari. Berikut kebutuhan air total setelah dilakukan perhitungan:

Kebutuhan Air $\quad=2562,74 \mathrm{~m}^{3} /$ hari

Kebutuhan Air $\quad=106,78 \mathrm{~m}^{3} / \mathrm{jam}$

Dari kebutuhan perhari kemudian dijadikan perjam. Kebutuhan air perjam dikalikan dengan faktor pengali kebutuhan air perjam berdasarkan jam pemakaian. 
NAROTAMA JURNAL TEKNIK SIPIL

e-ISSN: $2460-3430$

VOLUME 3 NOMOR 2 NOVEMBER 2019

Tabel 7. Volume Tampungan Reservoir Optimal

\begin{tabular}{|c|c|c|c|c|}
\hline t (jam) & Qd (m3/jam) & Qs(m3/jam) & Qs-Qd & V. Tandon (m3) \\
\hline 0 & & & & 200.00 \\
\hline 1 & 34.17 & 126.00 & 91.83 & 200.00 \\
\hline 2 & 44.85 & 126.00 & 81.15 & 200.00 \\
\hline 3 & 49.12 & 126.00 & 76.88 & 200.00 \\
\hline 4 & 73.68 & 126.00 & 52.32 & 200.00 \\
\hline 5 & 102.51 & 126.00 & 23.49 & 200.00 \\
\hline 6 & 143.09 & 126.00 & -17.09 & 182.91 \\
\hline 7 & 153.76 & 126.00 & -27.76 & 155.15 \\
\hline 8 & 193.27 & 126.00 & -67.27 & 87.88 \\
\hline 9 & 163.37 & 126.00 & -37.37 & 50.51 \\
\hline 10 & 160.17 & 126.00 & -34.17 & 16.34 \\
\hline 11 & 137.75 & 126.00 & -11.75 & 4.59 \\
\hline 12 & 119.59 & 126.00 & 6.41 & 11.00 \\
\hline 13 & 119.59 & 126.00 & 6.41 & 17.40 \\
\hline 14 & 101.44 & 126.00 & 24.56 & 41.96 \\
\hline 15 & 119.59 & 126.00 & 6.41 & 48.37 \\
\hline 16 & 119.59 & 126.00 & 6.41 & 54.77 \\
\hline 17 & 134.54 & 126.00 & -8.54 & 46.23 \\
\hline 18 & 139.88 & 126.00 & -13.88 & 32.35 \\
\hline 19 & 126.00 & 126.00 & 0.00 & 32.35 \\
\hline 20 & 102.51 & 126.00 & 23.49 & 55.84 \\
\hline 21 & 95.03 & 126.00 & 30.97 & 86.81 \\
\hline 22 & 73.68 & 126.00 & 52.32 & 139.13 \\
\hline 23 & 46.98 & 126.00 & 79.02 & 200.00 \\
\hline 24 & 22.42 & 126.00 & 103.58 & 200.00 \\
\hline Total & 2576.60 & 3024.00 & & \\
\hline
\end{tabular}

Sumber:Hasil Perhitungan, 2019

Volume Tamppungan Reservoir jika digambarkan dalam bentuk grafik seperti gambar 2 dibawah ini.

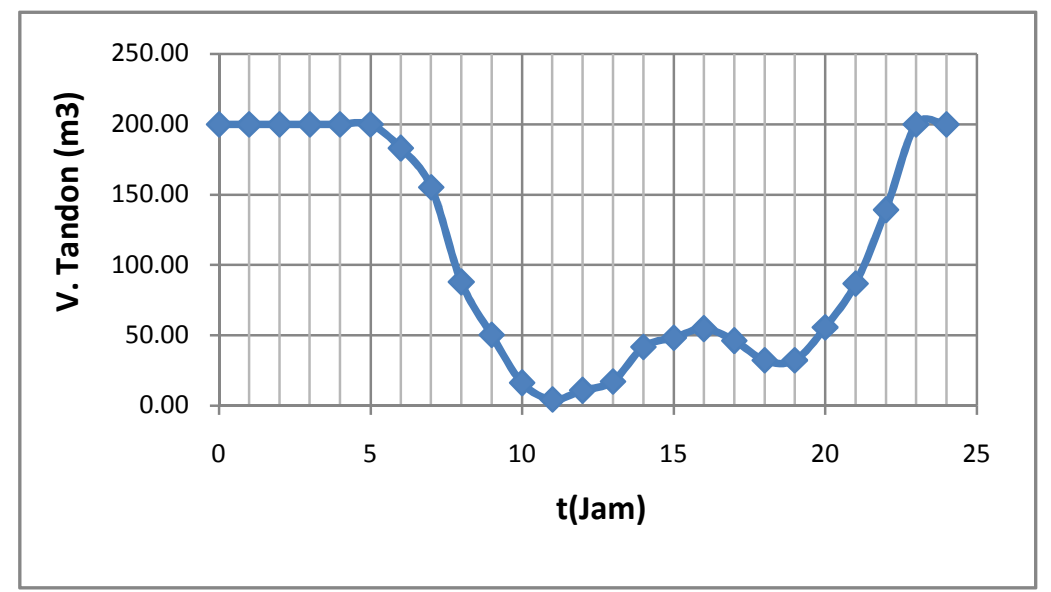

Gambar 2. Grafik Volume Tampungan Reservoir Optimal Sumber:Hasil Analisis Data, 2019

Dari hasil analisis maka ditentukan jika tampungan reservoir yang sesuai dengan kebutuhan air di Pulau Mandangin adalah $200 \mathrm{~m}^{3}$. 


\section{NAROTAMA JURNAL TEKNIK SIPIL \\ e-ISSN: $2460-3430$ \\ VOLUME 3 NOMOR 2 NOVEMBER 2019}

\section{KESIMPULAN}

a. Jumlah penduduk di Pulau Mnadangin sampai tahun 2023 di prediksi menggunakan Metode Aritmatik, pada tahun 2023 jumlah penduduknya mencapai 20694 Jiwa dengan targer jumlah penduduk yang terlayani pada analisis ini adalah $100 \%$;

b. Kebutuhan air pada tahun 2023 yang dilayani dengan Sambungan Rumah adalah sebesar $1655.5 \mathrm{~m}^{3} / \mathrm{dtk}$, kebutuhan yang dilayani dengan Hidran Umum adalah 124.16 $\mathrm{m}^{3} / \mathrm{dtk}$ jadi kebutuhan Kebutuhan air tahun 2023 untuk domestik $1779.6 \mathrm{~m}^{3} / \mathrm{dtk}$ non domestik $355.93 \mathrm{~m}^{3} / \mathrm{dtk}$ maka kebutuhan air total tahun 2023 adalah $2135.6 \mathrm{~m}^{3} / \mathrm{dtk}$;

c. Kebutuhan air rata-rata perhari adalah $2562.7 \mathrm{~m}^{3} / \mathrm{dtk}$ kebutuhan air maksimal perhari $2819.1 \mathrm{~m}^{3} / \mathrm{dtk}$ kebutuhan air pada jam puncak adalah $3844.1 \mathrm{~m}^{3} / \mathrm{dtk}$;

d. Dari evaluasi pembebanan debit, maka debit yang ada saat ini harus ditingkatkan, dari yang semula 5 1/dtk menjadi 301/dtk;

e. Berdasarkan analisis data didapatkan tampungan reservoir yang sesuai untuk kebutuhan air adalah $200 \mathrm{~m} 3$.

\section{DAFTAR PUSTAKA}

1. Buletin Cipta Karya Edisi 8/Tahun X/Agustus 2012. Reserve Osmosis Hapus Dahaga Nelayan Pulau Mandangin.Jakarta: PU Cipta Karya (http://Google.ReserveOsmosisHapusDahagaNelayanPulauMandangin ).

2. PP No. 20 Tahun 1990 Tentang Pengendalian Pencemaran Air.

3. PU Cipta Karya. 2010. Petunjuk Praktis Perencanaan Pembangunan Sistem Penyediaan Air Bersih Pedesaan Departemen Pekerjaan Umum (http://Google.PetunjukPerencaan AirBersih).

4. Pedesaan Departemen Pekerjaan Umum

5. (http://Google.PetunjukPerencaan AirBersih).

6. Trihatmodjo,Bambang. 2011. Hidraulika II. Jakarta: Beta Offset.

7. Trihatmodjo,Bambang. 2014. Hidraulika I. Jakarta: Beta Offset.

8. Unikom.2010.Metode Proyeksi Penduduk (http://elib.unikom.ac.id/files).

9. Pedesaan Departemen Pekerjaan Umum (http://Google.PetunjukPerencaan AirBersih).

10. Trihatmodjo,Bambang. 2011. Hidraulika II. Jakarta: Beta Offset.

11. Trihatmodjo,Bambang. 2014. Hidraulika I. Jakarta: Beta Offset.

12. Unikom.2010.Metode Proyeksi Penduduk (http://elib.unikom.ac.id/files). 